\title{
Excercised Muscles and the Brain
}

\section{Karim A Alkadhi*}

Department of Pharmacological and Pharmaceutical Sciences, USA

Epidemiological and experimental studies indicate the beneficial effects of regular physical activity in a variety of conditions, including age-related neurodegenerative disorders such as Alzheimer's disease and other dementias as well as brain injury [1-3].Exercised animals performed better in the spatial memory tasks (e.g. Morris water maze or radial arm water maze) compared to sedentary animals [4,5]. Similarly, exercise can improve non-spatial memory as tested in the passive avoidance paradigm and object recognition tasks $[4,6,7]$. Furthermore, animal experiments showed that treadmill exercise prevented memory impairment in sleep deprivation [8] dementia of the Alzheimer's type [9] and in rats treated with alcohol [10] streptozocin [11] or reserpine [12].

The neuroprotective effect of exercise is thought to be mediated by various molecular mechanisms including upregulation of neurotrophic factors and other molecules associated with learning and memory function, which in turn preserve and strengthen synaptic function leading to memory improvement.

We have shown that regular treadmill exercise reverses memory loss and synaptic plasticity impairment in a rat model of Alzheimer's disease as well as in sleep deprived rats. Additionally, exercise prevented impairment of Long-Term Potentiation (LTP) and normalized levels of the synaptic plasticity- and memory-related signaling molecules in these disorders $[8,9,13]$. In particular, our studies showed a marked increase in the levels of Brain Derived Neurotropic Factor (BDNF), which supported the prevailing belief that the beneficial effect of exercise may be due to increasing the availability of endogenous neurotrophic factors including BDNF.

\section{How does an Active Skeletal Muscle Communicate with the Brain?}

Clearly, there is ample evidence for the beneficial effect of exercise in a variety of brain disorders; however an important question remains unclear. How does muscle activity translate into a beneficial effect on the brain? The contracting muscles may communicate with the brain either through an endocrine mechanism or perhaps through afferent impulses originating from the active muscles. The latter possibility, however, seems unlikely inasmuch as it has been reported that in individuals with severed spinal cord or those under epidural anesthesia (no afferent or efferent impulses), contraction of paralyzed muscles by electrical stimulation produces physiological changes similar to those of normal individuals $[14,15]$. The alternative, therefore, is that skeletal muscles communicate with other organs through factor(s) released into the circulation during exercise. This possibility has been thoroughly discussed in a number of topical reviews by Pedersen and colleagues [16].

Brain-Derived Neurotrophic Factor (BDNF) is a member of the structurally related family of growth factors known as neurotrophins that affect neurons primarily by activating a number of Tyrosine kinase (Trk) receptors. BDNF and its receptor, TrkB, are most widely expressed in the brain [17]. However, it appears that BDNF is expressed not only in brain tissue but also in skeletal muscle [18]. This neurotrophin is important in regulating survival, growth and maintenance of neurons [19] and may figure prominently in cognitive function as suggested by deficient levels in neurodegenerative diseases [20]. In fact, it has been suggested that that plasma BDNF levels may be used as a biomarker of impaired cognitive function [21].

Exercise enhances BDNF transcription in the brain [22] and increases BDNF blood levels in healthy humans [23-25].The production of BDNF in the brain is activity dependent [26] where it can be stored and released in the dendrites and axons of hippocampal neurons. Like other neurotrophic factors, BDNF regulates activity-dependent protein synthesis and stimulate its own release at synaptic sites allowing for regenerative signaling for extended periods [27]. Since it is known that muscles produce BDNF during exercise, BDNF seems an obvious candidate for a messenger that communicates skeletal muscle activity to the central nervous system. This, however, turned out to be not the case.

\section{Brain-Derived Neurotrophic Factor (BDNF) is Produced in Exercised Muscle}

Initial studies showed a significant production of BDNF both at rest and during prolonged exercise in healthy male volunteers and this was thought to be the major source for increased plasma BDNF during exercise [28,29]. Later, however, muscle cell cultures experiments as well as human studies showed that although BDNF was markedly increased in exercised muscle cells, it was not released into the circulation [18] Thus, although BDNF is increased in contracting muscle cells, muscles are not a source of circulating BDNF. Rather, it is postulated, the BDNF produced by muscle during exercise stays in the muscle, perhaps to serve in an autocrine and/or paracrine capacity [16]. If that is the case, then where does BDNF in the circulation come from? It has been reported that at rest, BDNF is released into the internal jugular vein, suggesting that brain tissue is the main contributor to the circulating BDNF [28]. Another contributor to the high levels of BDNF during exercise is blood platelets, which are known to store and release $\mathrm{BDNF}$ [30]. It has been suggested that the enhanced levels of circulating BDNF during exercise may, at least in part, due to release of BDNF from activated platelets [18]. This has been confirmed by a study in healthy individuals who show significant increases in BDNF levels in serum, plasma and platelet immediately after the exercise [31].

\section{A Role for Cytokines}

Another possible messenger that can be involved in the signaling mechanism between active skeletal muscles and the brain are the cytokines. Cytokines are pro-inflammatory and anti-inflammatory low

*Corresponding author: Karim A Alkadhi, Department of Pharmacological and Pharmaceutical Sciences, 521E Science and Research 2 Bldg, College of Pharmacy, University of Houston, Houston, TX 77204-5037, USA, Tel: 713-7431212; Fax: 713-743-1229; E-mail: phar11@Central.UH.EDU

Received November 19, 2012; Accepted November 21, 2012; Published November 23, 2012

Citation: Alkadhi KA (2012) Excercised Muscles and the Brain. Clin Exp Pharmacol 2:e116. doi:10.4172/2161-1459.1000e116

Copyright: (c) 2012 Alkadhi KA. This is an open-access article distributed under the terms of the Creative Commons Attribution License, which permits unrestricted use, distribution, and reproduction in any medium, provided the original author and source are credited. 
molecular weight glycoprotein molecules, which act as intercellular messengers. Muscles release cytokines into the blood circulation and these may exert specific endocrine effects on distant organs. The levels of Interleukin-6 (IL-6), the first cytokine reported to be secreted into the bloodstream during muscle contractions [32], were markedly increase in response to exercise. Previously, it was thought that the increase in IL-6 levels during exercise was a result of release from macrophages as an immune response to local damage in the contracting muscles $[33,34]$. It has been shown that labeled IL- 6 crosses the blood brain barrier by a saturable transport system and, although only a small fraction of intact IL-6 survives in the cerebrospinal fluid or brain tissue, it may be sufficient to produce biological effects $[35,36]$.It is tempting to speculate that cytokines released during muscle contraction may stimulate the release of BDNF from platelets thus increasing its levels in the cerebral blood circulation and Cerebrospinal Fluid (CSF). In support of this possibility, it has been reported that BDNF expression in the CSF was strongly correlated with IL-6 levels in the CSF and with blood platelet counts [37].

Obviously, more future work is needed to definitively clarify the mechanism of cross-talk between contracting muscle and the brain and how muscle activity translates into beneficial effects on the brain and other organs. Deciphering the molecular mechanism of this pathway will facilitate the discovery of drugs that mimic exercise, which would be greatly beneficial in physically challenged individuals.

\section{References}

1. Bohannon RW (1993) Physical rehabilitation in neurologic diseases. Curr Opin Neurol 6: 765-772.

2. Grealy MA, Johnson DA, Rushton SK (1999) Improving cognitive function after brain injury: the use of exercise and virtual reality. Arch Phys Med Rehabil 80: 661-667.

3. Cotman CW, Berchtold NC, Christie LA (2007) Exercise builds brain health: key roles of growth factor cascades and inflammation. Trends Neurosci 30: 464-472.

4. Grace L, Hescham S, Kellaway LA, Bugarith K, Russell VA (2009) Effect of exercise on learning and memory in a rat model of developmental stress. Metab Brain Dis 24: 643-657.

5. Khabour OF, Alzoubi KH, Alomari MA, Alzubi MA (2010) Changes in spatial memory and BDNF expression to concurrent dietary restriction and voluntary exercise. Hippocampus 20: 637-645.

6. Alaei H, Borjeian L, Azizi M, Orian S, Pourshanazari A, et al. (2006) Treadmill running reverses retention deficit induced by morphine. Eur $\mathrm{J}$ Pharmacol 536: 138-141.

7. Hopkins ME, Bucci DJ (2010) Interpreting the effects of exercise on fear conditioning: the influence of time of day. Behav Neurosci 124: 868-872.

8. Zagaar M, Alhaider I, Dao A, Levine A, Alkarawi A, et al. (2012) The beneficial effects of regular exercise on cognition in REM sleep deprivation: behavioral, electrophysiological and molecular evidence. Neurobiol Dis 45: 1153-1162.

9. Dao An, Zagaar Munder, Amber Levine, Samina Salim, Karim Alkadhi. Treadmill exercise prevents learning and memory impairment in Alzheimer's disease-like pathology. Current Alzheimer Research.

10. Helfer JL, Goodlett CR, Greenough WT, Klintsova AY (2009) The effects of exercise on adolescent hippocampal neurogenesis in a rat model of binge alcohol exposure during the brain growth spurt. Brain Res 1294: 1-11.

11. Reisi P, Alaei H, Babri S, Sharifi MR, Mohaddes G (2009) Effects of treadmill running on spatial learning and memory in streptozotocin-induced diabetic rats. Neurosci Lett 455: 79-83.

12. Aguiar AS Jr, Araújo AL, da-Cunha TR, Speck AE, Ignácio ZM, et al. (2009) Physical exercise improves motor and short-term social memory deficits in reserpinized rats. Brain Res Bull 79: 452-457.

13. Munder Z, Alhaider I, An Dao, Levine A, Alkadhi K. Regular exercise prevents sleep deprivation associated impairment of long-term memory, synaptic plasticity and its signaling cascade in the CA1 area of the hippocampus. Sleep.

14. Kjaer M, Secher NH, Bangsbo J, Perko G, Horn A, et al. (1996) Hormonal and metabolic responses to electrically induced cycling during epidural anesthesia in humans. J Appl Physiol 80: 2156-2162.

15. Mohr T, Andersen JL, Biering-Sørensen F, Galbo H, Bangsbo J, et al. (1997) Long-term adaptation to electrically induced cycle training in severe spinal cord injured individuals. Spinal Cord 35: 1-16.

16. Pedersen BK, Febbraio MA (2012) Muscles, exercise and obesity: skeletal muscle as a secretory organ. Nat Rev Endocrinol 8: 457-65.

17. Huang EJ, Reichardt LF (2001) Neurotrophins: roles in neuronal development and function. Annu Rev Neurosci 24: 677-736.

18. Matthews VB, Aström MB, Chan MH, Bruce CR, Krabbe KS, et al. (2009) Brainderived neurotrophic factor is produced by skeletal muscle cells in response to contraction and enhances fat oxidation via activation of AMP-activated protein kinase. Diabetologia 52: 1409-1418.

19. Mattson MP, Maudsley S, Martin B (2004) BDNF and 5-HT: a dynamic duo in age-related neuronal plasticity and neurodegenerative disorders. Trends Neurosci 27: 589-594.

20. Zuccato C, Cattaneo E (2009) Brain-derived neurotrophic factor in neurodegenerative diseases. Nat Rev Neurol 5: 311-322.

21. Komulainen $P$, Pedersen $M$, Hänninen $T$, Bruunsgaard $H$, Lakka TA, et al (2008) BDNF is a novel marker of cognitive function in ageing women: the DR's EXTRA Study. Neurobiol Learn Mem 90: 596-603.

22. Oliff HS, Berchtold NC, Isackson P, Cotman CW (1998) Exercise-induced regulation of brain-derived neurotrophic factor (BDNF) transcripts in the rat hippocampus. Brain Res Mol Brain Res 61: 147-153.

23. Gold SM, Schulz KH, Hartmann S, Mladek M, Lang UE, et al. (2003) Basal serum levels and reactivity of nerve growth factor and brain-derived neurotrophic factor to standardized acute exercise in multiple sclerosis and controls. J Neuroimmunol 138: 99-105.

24. Rojas Vega S, Strüder HK, Vera Wahrmann B, Schmidt A, Bloch W, et al. (2006) Acute BDNF and cortisol response to low intensity exercise and following ramp incremental exercise to exhaustion in humans. Brain Res 1121: 59-65.

25. Ferris LT, Williams JS, Shen CL (2007) The effect of acute exercise on serum brain-derived neurotrophic factor levels and cognitive function. Med Sci Sports Exerc 39: 728-734.

26. Johnson RA, Mitchell GS (2003) Exercise-induced changes in hippocampa brain-derived neurotrophic factor and neurotrophin-3: effects of rat strain. Brain Res 983: 108-114.

27. Bramham CR, Messaoudi E (2005) BDNF function in adult synaptic plasticity: the synaptic consolidation hypothesis. Prog Neurobiol 76: 99-125.

28. Krabbe KS, Nielsen AR, Krogh-Madsen R, Plomgaard P, Rasmussen $P$, et al. (2007) Brain-derived neurotrophic factor (BDNF) and type 2 diabetes. Diabetologia 50: 431-438.

29. Rasmussen P, Brassard P, Adser H, Pedersen MV, Leick L, et al. (2009) Evidence for a release of brain-derived neurotrophic factor from the brain during exercise. Exp Physiol 94: 1062-1069.

30. Fujimura H, Altar CA, Chen R, Nakamura T, Nakahashi T, et al. (2002) Brainderived neurotrophic factor is stored in human platelets and released by agonist stimulation. Thromb Haemost 87: 728-734.

31. Cho HC, Kim J, Kim S, Son YH, Lee N, et al. (2012) The concentrations of serum, plasma and platelet BDNF are all increased by treadmill VOâ,,max performance in healthy college men. Neurosci Lett 519: 78-83.

32. Pedersen BK, Febbraio MA (2008) Muscle as an endocrine organ: focus on muscle-derived interleukin-6. Physiol Rev 88: 1379-1406.

33. Nehlsen-Cannarella SL, Fagoaga OR, Nieman DC, Henson DA, Butterworth $\mathrm{DE}$, et al. (1997) Carbohydrate and the cytokine response to $2.5 \mathrm{~h}$ of running J Appl Physiol 82: 1662-1667.

34. Nieman DC, Nehlsen-Cannarella SL, Fagoaga OR, Henson DA, Utter A, et al. (1998) Influence of mode and carbohydrate on the cytokine response to heavy exertion. Med Sci Sports Exerc 30: 671-678.

35. Banks WA, Kastin AJ, Gutierrez EG (1994) Penetration of interleukin-6 across the murine blood-brain barrier. Neurosci Lett 179: 53-56. 
Citation: Alkadhi KA (2012) Excercised Muscles and the Brain. Clin Exp Pharmacol 2:e116. doi:10.4172/2161-1459.1000e116

Page 3 of 3

36. Pan W, Kastin AJ (2007) Adipokines and the blood-brain barrier. Peptides 28 1317-1330.

37. Morichi S, Kashiwagi Y, Takekuma K, Hoshika A, Kawashima H (2012)
Expressions of brain-derived neurotrophic factor (BDNF) in cerebrospinal fluid and plasma of children with meningitis and encephalitis/encephalopathy. Int $J$ Neurosci. 